\title{
Surgical Treatment for Left Main Coronary Atresia with Significant Mitral Regurgitation in a 1-Year-Old Child
}

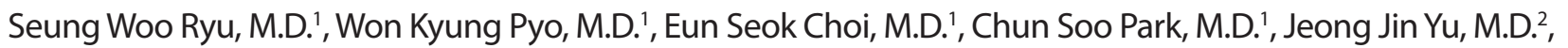 \\ Tae-Jin Yun, M.D. ${ }^{1}$, Cheol Hyun Chung, M.D., Ph.D. ${ }^{1}$ \\ Departments of 'Thoracic and Cardiovascular Surgery and 2Pediatrics, Asan Medical Center, University of Ulsan College of Medicine, Seoul, Korea
}

\section{ARTICLE INFO}

Received June 9, 2020

Revised July 1, 2020

Accepted July 2, 2020

Corresponding author

Cheol Hyun Chung

Tel 82-2-3010-3580

Fax 82-2-3010-6966

E-mail hyun227@amc.seoul.kr

ORCID

https://orcid.org/0000-0001-8981-6011

\begin{abstract}
Congenital atresia of the left main coronary artery (LMCA) is an extremely rare coronary anomaly that necessitates surgical correction. Patients with LMCA atresia may have various clinical symptoms, which are determined by the degree of collateral vessel development from the right coronary system, the metabolic demands of the heart, and concomitant mitral insufficiency caused by myocardial ischemia. Unlike in adults, there are limited surgical options for coronary artery disease in children. Herein, we report a case of LMCA atresia with mitral regurgitation in a 19-month-old child that was successfully corrected by coronary artery bypass grafting and mitral valve repair.
\end{abstract}

Keywords: Congenital heart disease, Coronary artery bypass, Mitral valve, Repair

\section{Case report}

A 15-month-old female child was referred to Asan Medical Center because of an incidentally found cardiac murmur. A chest X-ray revealed mild cardiomegaly, and an electrocardiogram showed no remarkable findings. Echocardiography showed preserved left ventricular function and moderate mitral regurgitation (MR), with prolapse of the anterior mitral leaflet and an echogenic anterolateral papillary muscle indicating ischemic changes. The right coronary artery was prominent, but the left main coronary artery (LMCA) was not identified on echocardiography. Computed tomography angiography demonstrated total occlusion of the proximal LMCA. Myocardial single photon emission computed tomography (SPECT) showed a reversible large decrease in perfusion in the anterior, anterolateral, and inferolateral wall. Coronary angiography confirmed that the proximal LMCA did not originate from any vessel or cardiac chamber, and the left coronary arteries received only retrograde flow through collaterals from the right coronary artery (Fig. 1).

She underwent surgical treatment at the age of 19 months. We planned coronary artery bypass grafting (CABG) if the target vessel and graft vessel were of an appropriate size. Surgical angioplasty was considered as the
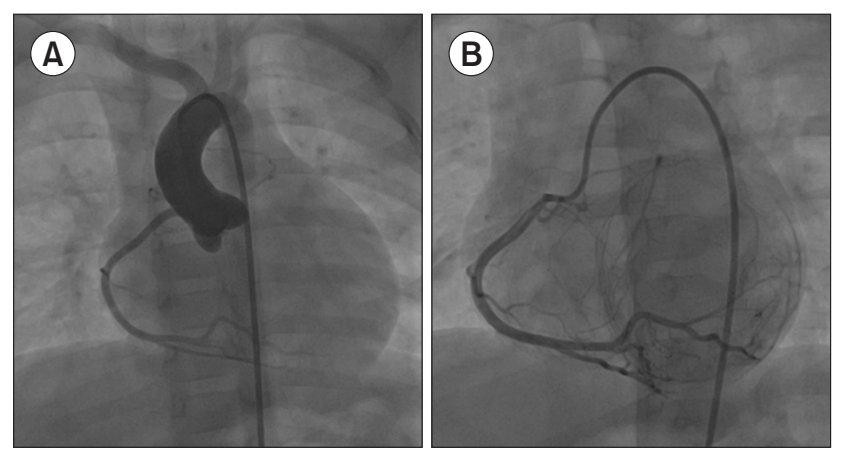

Fig. 1. Preoperative coronary angiography. (A) Aortic root angiography demonstrating the absence of left coronary artery filling. (B) Coronary angiography showing the dilated right coronary artery with collaterals filling the branches of the left coronary artery.

second treatment option, because the left main coronary atresia lesion extended to near the bifurcation of the left anterior descending (LAD) artery and left circumflex artery. We inspected the diameter of the left internal mammary artery (LIMA) and the LAD artery to confirm that CABG was technically feasible, and found that both diameters were $1 \mathrm{~mm}$. A LIMA graft was then harvested in a skeletonized manner and anastomosed to the proximal LAD artery with the on-pump beating-heart technique. The anastomosis was performed using 8-0 Prolene run- 

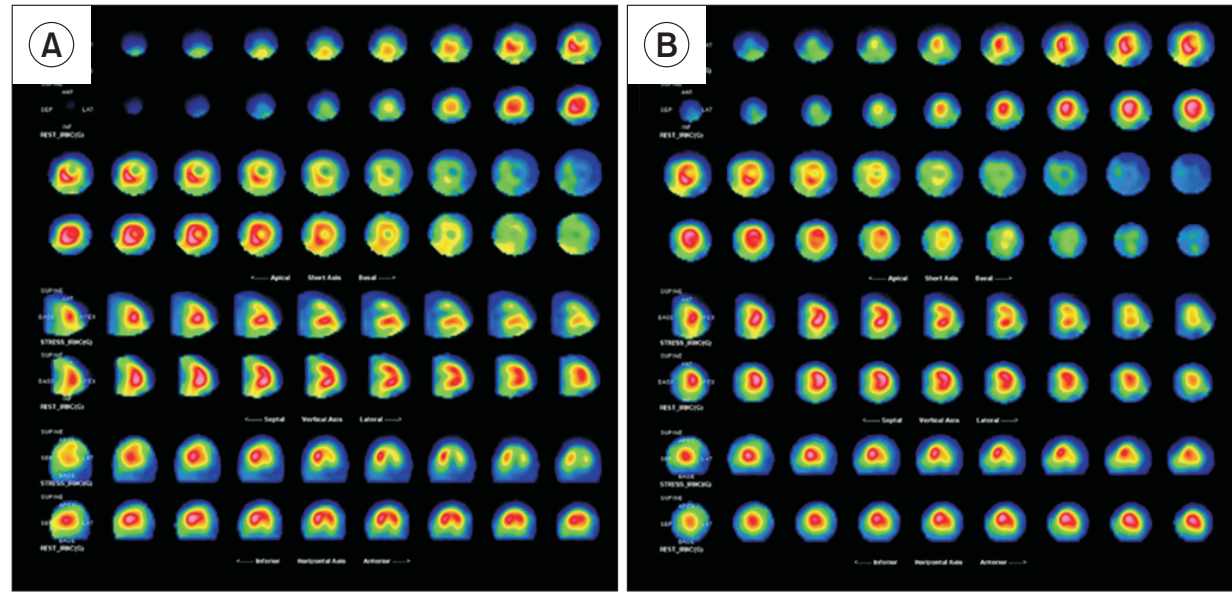

Fig. 2. Preoperative and postoperative myocardial SPECT. (A) Preoperative myocardial SPECT showing reversible, large, moderately decreased perfusion in the anterior, anterolateral, and inferolateral wall. (B) Postoperative myocardial SPECT showing partially improved myocardial perfusion in the anterior and anterolateral wall. SPECT, single photon emission computed tomography.

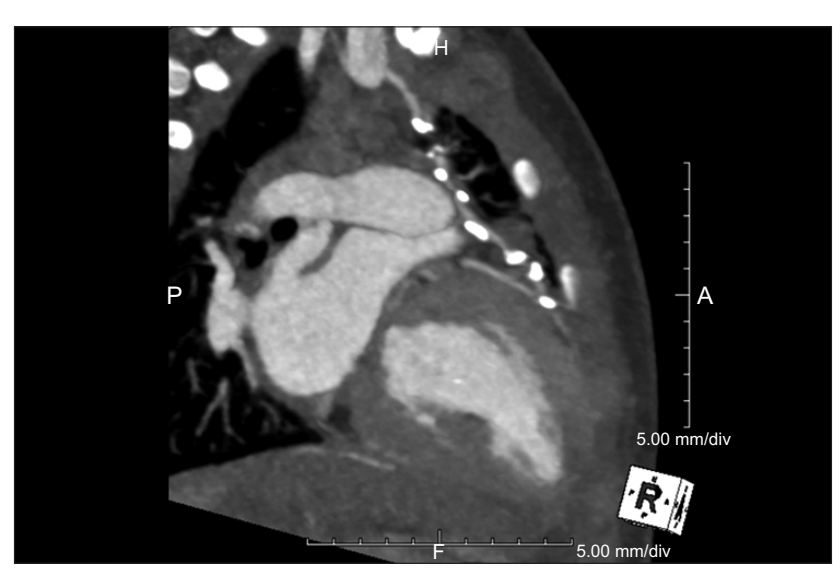

Fig. 3. Postoperative computed tomography angiography showing that the left internal mammary artery graft was patent, with good distal run-off in the left anterior descending artery.

ning sutures with an intracoronary shunt in place to maintain distal coronary perfusion and to provide a bloodless field. We measured the transit time for the assessment of graft patency and showed a satisfactory flow curve (mean flow $>15 \mathrm{~mL} / \mathrm{min}$, pulsatility index $<2$ ). We performed concomitant mitral valve repair because the mitral valve had structural changes with preserved left ventricular function. The mitral valve was repaired with techniques including resection of the calcified and elongated anterolateral papillary muscle, the formation of neo-chordae to the anterior mitral leaflet, and partial annuloplasty. The postoperative hospital course was uneventful and she was discharged from the hospital on postoperative day 18. Postoperative echocardiography showed good left ventricular function and mild MR. Postoperative computed tomography angiography demonstrated that the LIMA graft was patent with good distal run-off of the LAD artery (Fig. 3).
Postoperative myocardial SPECT showed partially improved myocardial perfusion (Fig. 2). Three months after discharge, the patient was seen at our outpatient clinic without any symptoms or abnormal laboratory findings.

The study was approved by the Institutional Review Board of Asan Medical Center (exemption confirmation no., 2020-1150). Informed consent was waived.

\section{Discussion}

Congenital LMCA atresia is quite rare, with only limited case reports found in the literature, totaling fewer than 70 cases [1]. Although concomitant abnormalities are not common, some children with this condition have other cardiac anomalies including bicuspid aortic valve, supravalvular aortic stenosis, pulmonary stenosis, and ventricular septal defect [2].

The diagnosis is made with coronary angiography and echocardiography, which enable differentiation of this condition from anomalous origin of the left coronary artery from the pulmonary artery and a single coronary artery [1] Coronary angiography is essential for evaluating collateral blood flow to the left coronary arteries, but it has risks such as coronary spasm. Multislice computed tomography has been used to evaluate coronary anomalies, but the efficacy of computed tomography in small children and infants is not fully clear [3].

Although symptoms depend on the development of collateral vessels from the right coronary artery to the left coronary artery, the heart eventually cannot bear the strain and symptoms occur. Infants mostly present with failure to thrive and myocardial infarction, while children and adolescents may present with syncope and rhythm disturbances. Adult patients may present with dyspnea, angina, 
or sudden death [4].

Hung [5] reported that the main mechanism of ischemic MR involves distortion of the spatial relationships between the mitral valve and papillary muscles secondary to myocardial infarction. In this case, the operative findings confirmed annulus dilatation and ischemic changes of the papillary muscle with calcification and elongation, and concomitant mitral valve repair was therefore necessary.

There are 2 options for the surgical treatment of LMCA atresia: surgical angioplasty and CABG. Six cases of surgical angioplasty in patients with congenital LMCA ostium atresia have been reported [6]. There were 2 cases of early mortality because the left ventricle was necrotic, and ventricular function did not recover despite successful revascularization. Although these early results are encouraging, surgical angioplasty is indicated in few cases, because the anatomy of the coronary artery precludes surgical angioplasty or the coronary artery lesion extends beyond the first segment. The literature contains mostly favorable reports regarding the outcomes of CABG $[1,7]$. The CABG procedure is technically challenging in these cases because the target vessel and potential graft are small. D'souza et al. [8] reported a successful case of CABG in a neonate using the LIMA, with good patency of the graft for 1 year after surgery. However, the long-term patency rate of CABG remains questionable in young children because of the scant available data. Postoperative outcomes are related to the degree of myocardial damage at the time of diagnosis and operation. Short-term outcomes after surgical revascularization are encouraging when the patient has adequate collateral vessels and the anomaly is promptly recognized.

LMCA atresia with MR is a rare condition. CABG is a reasonable surgical option in LMCA atresia if it is technically feasible. Herein, we describe surgical revascularization using CABG and mitral valve repair in a 19-monthold child with acceptable early outcomes. However, longterm graft patency is uncertain, and careful follow-up is therefore mandatory.

\section{Conflict of interest}

No potential conflict of interest relevant to this article was reported.

\section{ORCID}

Seung Woo Ryu: https://orcid.org/0000-0001-6155-0063 Won Kyung Pyo: https://orcid.org/0000-0002-5769-052X Eun Seok Choi: https://orcid.org/0000-0002-0618-4686 Chun Soo Park: https://orcid.org/0000-0001-8718-8904 Jeong Jin Yu: https://orcid.org/0000-0003-1601-3685

Tae-Jin Yun: https://orcid.org/0000-0002-0336-1720

Cheol Hyun Chung: https://orcid.org/0000-0001-8981-6011

\section{References}

1. Sellke FW, del Nido PJ, Swanson SJ. Sabiston and Spencer surgery of the chest. 9th ed. Philadelphia (PA): Elsevier; 2015.

2. Satran A, Dawn B, Leesar MA. Congenital ostial left main coronary artery stenosis associated with a bicuspid aortic valve in a young woman. J Invasive Cardiol 2006;18:E114-6.

3. Sohn SY, Jang GY, Choi BM. Congenital atresia of the left main coronary artery in an infant. J Zhejiang Univ Sci B 2010;11:539-41.

4. Tian M, Wang X, Gao H, Wang L, Hu S. Left main coronary artery atresia with concomitant mitral regurgitation in an adult: a case report. Medicine (Baltimore) 2018;97:e12367.

5. Hung JW. Ischemic (functional) mitral regurgitation. Cardiol Clin 2013;31:231-6

6. Kaczorowski DJ, Sathanandam S, Ravishankar C, et al. Coronary ostioplasty for congenital atresia of the left main coronary artery ostium. Ann Thorac Surg 2012;94:1307-10.

7. Min SK, Choi SH, Jang WS, Lee JH, Kim CY, Kim WH. Congenital left main coronary artery atresia. Korean J Thorac Cardiovasc Surg 2006;39:779-81.

8. D'Souza TF, Samuel BP, Vettukattil JJ, Haw MP. Surgical treatment of neonate with congenital left main coronary artery atresia. Ann Thorac Surg 2016;101:352-5. 